\title{
Civil Servants' Perceptions of Agency Heads' Leadership Styles: The Role of Gender in Public Sector Organizations
}

\author{
Don S. Lee \\ School of Politics and International Relations \\ University of Nottingham \\ Soonae Park \\ Graduate School of Public Administration \\ Seoul National University
}

Accepted in Public Management Review on 4 February 2020

\begin{abstract}
In this article, we examine public employees' perceptions of agency heads' leadership styles by focusing on the role of gender in organizational management. Employing an original survey experiment with over 800 national civil servants in South Korea, we find that female employees have more positive perceptions of transformational leadership than male employees; however, female and male employees' perceptions of transactional leadership are not significantly different. Moreover, employee gender, when investigated along with gender representation in organizations, produces more nuanced results. An increase in women's representation in public sector organizations leads to more positive perceptions of transformational leadership behaviors among female than male employees, but it does not change perceptions of transactional leadership behaviors among female and male employees. Our findings suggest a clear gender gap in perceptions of leadership styles among public employees, and these differences are further unpacked with variations in gender representation in public sector organizations.
\end{abstract}

Keywords: Public Leadership, Gender and Representation, Civil Servant Perception, Survey

Experiment 
Much of public administration research has emphasized that leadership plays an essential role in enhancing performance in public sector organizations (Andrews \& Boyne, 2010; Meier \& O'Toole, 2002; van Wart, 2003). However, scholars are still far from consensus on which leadership styles are more important in which contexts (Fernandez, 2005; Rainey, 2009; Trottier, van Wart, \& Wang, 2008; van Wart, 2013). Evidence from observational studies shows that transformational leadership may improve the regular operations of public sector organizations (Mary, 2005; Paarlberg \& Lavigna, 2010; Park \& Rainey, 2008; Rowold \& Rohmann, 2009; Trottier et al., 2008). Yet, other observational studies suggest that transformational leadership may not be as effective as transactional leadership in a public agency setting, due to the hierarchical nature of the organizations (Wright \& Pandey, 2010). Experimental or quasiexperimental studies also show mixed findings about the impact of leadership styles on organizational performance management (Bellé, 2014; Dvir et al., 2002; Grant, 2012).

In this study, we examine perceptions of leadership styles by focusing on the role of gender in public sector organizations. In the leadership literature, there is expansive research on how gender affects employees' perceptions of leadership styles (e.g., Bass, Avolio, \& Atwater, 1996; Carli \& Eagly, 2011; Collins, Burrus, \& Meyer, 2014; Collinson, 2005; Eagly \& Carli, 2007; Eagly \& Heilman, 2016). Public administrative research also increasingly highlights gender effects and dynamics in public settings. Public employees tend to build more positive relationships with their managers who are of the same gender (Hassan \& Hatmaker, 2015) and experience lower satisfaction and greater turnover under supervisors who are of different genders (Grissom, Nicholson-Crotty, \& Keiser, 2012). Despite the robust research agenda, few studies investigate how gendered conditions at the organizational level affect the perceptions of leadership styles. 
In assessing the factors that shape perceptions of leadership styles in public sector organizations, we focus on the gender of the employee and gender representation in the organization. Building on prior discussion of central aspects of two distinct leadership models transactional and transformational (Bass, 1985; Burns, 1978; Jensen et al., 2016; Trottier et al., 2008), we address the following research questions: How does subordinate gender affect the perceived importance of different leadership styles? How does the extent to which the organizational context is gendered reshape employees' perceptions? We provide followercentered (Bligh, 2011; Riggio, Chaleff, \& Lipman-Blumen, 2008; Shamir et al., 2007) and constructionist approaches (Vogel \& Masal, 2015). The former challenges traditional assumptions by recognizing followers as a critical part of the leadership process, and the latter views the organizational context as the conditions that encourage the emergence of particular forms of leadership.

We seek to answer these questions with a unique survey design of list experiments with over 800 central government employees in South Korea (henceforth Korea), gathered as part of a nationally representative survey. We also use existing variations in gender representation in public agencies, to provide a non-experimental test of whether the degree to which the organization is gendered affects perceptions of significant leadership behavior. Recently adopted statistical methods permitting multivariate analysis of list experiment data enable us to unravel how such perceptions change with subordinate gender and gender representation in the organization, while controlling for other individual and organizational characteristics. We find that in organizational management, female civil servants have more positive perceptions of transformational leadership than male civil servants, but perceptions of transactional leadership are not significantly different across civil servant gender. We also find that employee gender 
produces more nuanced results, interacting with the organizational context. Male civil servants' perceptions of transformational leadership have a negative relationship with women's representation in the organization. Female civil servants' perceptions of transactional leadership are positive in highly male-dominated organizations, but such perceptions are attenuated with an increase in women's representation in the organization. Our findings show a clear gender gap in perceptions of leadership styles, and these differences are further unpacked with variations in gender representation in public sector organizations.

This study focuses particularly on employee gender and gender representation in public settings, to address important policy implications, as well as to contribute to our understanding of public sector leadership and organizations. Research on gender and public management suggests that the representation of employees' gender affects not only the degree to which public organizations assist clients of different genders (Keiser et al., 2002; Meier \& Nicholson-Crotty, 2006; Wilkins \& Keiser, 2006) but also the types of policies and state bureaucracies adopted for minorities (Atchison \& Down, 2009; Lee \& Park, 2018; True \& Mintrom, 2001). Although public sector organizations may be more formalized, and their authority structure can be more hierarchical (Wright \& Pandey, 2010), our analysis shows that the perceived importance of leadership styles depends on individual and organizational characteristics in the public sector.

In the next sections, we review existing research on transactional and transformational leadership models, and the role of gender in employees' perceptions of leadership and the organizational context. From this discussion, we derive a set of testable hypotheses about the effect of civil servant gender, and its interaction with gender representation in the organization. Then, we describe our survey methods and experimental design, followed by presenting our findings in detail. We discuss some important implications of our findings for public 
management practice and conclude by offering some suggestions regarding how future research, built on the foundation of our key findings, could proceed in various directions.

\section{Transactional and Transformational Leadership in Public Sector Organizations}

Before developing our hypotheses, we will revisit the leadership literature, where different leadership styles are conceived in different ways, in order to distinguish our notion of transactional and transformational leadership. Then, we will discuss how this notion is applied specifically to the question of subordinate perceptions, and how these perceptions vary depending on public employees' individual and organizational characteristics.

According to the theories and models of leadership, transactional and transformational leadership form the active elements of the "full range" leadership model (Bass, 1985). The two leadership styles are distinct (Burns, 1978; Lowe, Kroeck, \& Sivasubramaniam, 1996); however, they are relational concepts that can be studied in tandem (Bass, 1985; Bass et al., 2003; Bass \& Riggio, 2006). Public administration research has conceptualized leadership behavior in public sector organizations by building on leadership theories and models, while emphasizing the aspect of "publicness," that is, the so-called "public leadership."

Empirical tests of leadership provide definitional concepts of leadership styles linked to specific organizational capabilities (Bycio, Hackett, \& Allen, 1995; Sosik, Avolio, \& Kahai, 1997; Waldman et al., 2001). At its core, transformational leadership involves motivating followers by linking an inspiring vision to core values of organizations (Shamir et al., 1998). It is a form of leadership particularly suited to promoting organizational change (Yukl, 2008). For this reason, it has been alternatively referred to as visionary leadership (Dvir et al., 2002). Therefore, existing observational and experimental studies commonly identify a leader's ability 
to arouse inspirational motivation through articulating an appealing vision as a key element of transformational leadership (e.g., Trottier et al., 2008, 321; Bellé, 2014; Dvir et al., 2002; Moynihan, Pandey, \& Wright, 2012).

Transactional leadership's central aspect is managerial and instrumental (Bass, 1985). In contrast to the concept of transformational leadership that is suited to fostering organizational change, transactional leadership centers on fulfilling current follower needs. In this sense, as existing studies suggest, the two main elements of transactional behavior are monitoring follower performance, and rewarding or punishing them to adhere to procedures (Bass, 1985; Burns, 1978; Trottier et al., 2008). Together, while transformational leaders communicate a vision of the organization's future and direct employees' behavior toward such a vision, transactional leaders monitor employee performance and use rewards and punishment to stick to organizational procedures. ${ }^{1}$

\section{Civil Servant Gender and Perception of Leadership Styles}

Having distinguished the two leadership styles, we can now ask the question: What's the role of gender in civil servants' perceptions of agency heads' leadership styles? We address this question by focusing on gender differences of public employees, and the extent to which the organizational context is gendered.

Previous studies on leadership tend to take leader-centric approaches, typically treating followers as outcomes and overlooking an important part, that is, follower perception (Hunter, Bedell-Avers, \& Mumford, 2007). However, recent research has redirected attention toward the role of followership in the leadership process, due to the "importance of followers' processes of

\footnotetext{
${ }^{1}$ We recognize a multidimensional aspect in conceptualizing leadership styles (Jensen et al., 2016) but maintain that the described features used here to conceptualize the two leadership styles are their core elements that are clearly distinct and can be applied to estimate changes in subordinate perceptions of these leadership styles empirically.
} 
attribution and sense-making in organizations" (Bligh, 2011, 427). ${ }^{2}$ Among this recent research, one approach to follower perception is to explore how follower attribution influences perceptions of leadership (Felfe \& Schyns, 2006; Schyns \& Bligh, 2007; Schyns \& Sanders, 2007). By examining the extent to which the assessment of leadership is a result of follower characteristics, these studies provide evidence that follower personalities affect the perception of transformational leadership. The evidence is centered on three separate bodies of research. First, leaders who are "prototypical," or representative of their followers' personalities, are perceived as more effective than others (e.g., Hogg, 2001; van Knippenberg et al., 2004). Second, followers and leaders with similar personalities are more likely to interact with each other (e.g., Meindl, 1993; Schneider, 1998). Third, followers who share characteristics with transformational leaders also perceive more transformational leadership in their own leaders (e.g., Watson, Hubbard, \& Wiese, 2000).

In this regard, follower gender is expected to be closely related to the perception of leadership style. According to the gender and leadership literature, men and women have different leadership styles, and followers of both genders share characteristics of these leaders by identifying with them (Alimo-Metcalfe, 1995; Bass, Avolio, \& Atwater, 1996; Carli \& Eagly, 2011; Collinson, 2005; Eagly \& Carli, 2007). In many leadership studies with different research methods, female managers are found to be more democratic and transformational but less autocratic and directive than male supervisors, across a variety of settings (Bass, Avolio, \& Atwater, 1996; Eagly, Johannesen-Schmidt, \& van Engen, 2003; van Engen \& Willemsen, 2004).

\footnotetext{
${ }^{2}$ As the precursor of a truly follower-centered approach to leadership, the romance of leadership perspective (Meindl, 1995) helps to produce empirical evidence that reveals "important insights into how followers conceptualize leader behaviors and their potential impacts" (Bligh, 2011, p. 428; Bligh et al., 2007). Uhl-Bien and Pillai (2007) suggest that followers can actively form their roles as partners or participants. In public administration research, there have been gradual shifts toward the influence of socially constructed views of followership in the leadership process. The quality of the relationships between public employees and their supervisors is one central factor discussed in the literature (Hassan \& Hatmaker, 2015; Vigoda-Gadot \& Beeri, 2012).
} 
Both female and male managers, on average, rely on the transactional leadership style, which indicates that gender differences would be less pronounced than in transformational leadership (Carli \& Eagly, 2011).

Research on follower gender and leadership in public administration also acknowledges gender effects and dynamics but often highlights the gender effects of the leader or supervisorsubordinate relations, rather than the follower alone (Grissom et al., 2012; Hassan \& Hatmaker, 2015). Building on the theories of relational demography and representative bureaucracy, these studies suggest that similar demographic characteristics between managers and employees have a positive impact on subordinate perceptions of leadership styles (e.g., Goldberg, Riordan, \& Schaffer, 2010; Goldberg, Riordan, \& Zhang, 2008). To the extent that employees reflect the characteristics of their leaders, we should expect that the perceptions of female and male employees will differ more in relation to a leadership style that is associated with either male or female managers. As existing studies suggest, female supervisors are found to be more transformational than male counterparts, but the features of transactional leadership are somewhat shared by female and male supervisors. Therefore, we predict that female employees have more positive perceptions of transformational leadership than male employees. However, gender differences in followers' perceptions toward transactional leadership will be less pronounced. This discussion leads to our first two hypotheses:

H1a: In organizational management, female employees have more positive perceptions of transformational leadership than male employees.

H1b: In organizational management, female and male employees' perceptions of transactional leadership are not significantly different. 


\section{Gender Representation and Perception of Leadership Styles}

In this section, we examine the role of gender representation in the organization, and its interplay with employee gender in perceptions of leadership styles. Research focusing on gender representation is particularly important in a public setting, because the representation of public employees' gender affects the degree to which public organizations assist clients of different genders (Keiser et al., 2002; Meier \& Nicholson-Crotty, 2006; Wilkins \& Keiser, 2006). More generally, as recent public administration research suggests, the internal context of an organization can influence the relationship between public management and performance (George, Van de Walle, \& Hammerschmid, 2019; Jacobsen \& Anderson, 2017; Kim \& Park, 2017; Lee, 2018, 2020; Luu, 2019; O’Toole \& Meier, 2015). First, it provides the main constraint on how managers use given resources in efforts to achieve organizational goals. Second, it also affects what managerial actions are necessary and likely to be important in goal accomplishment (O'Toole \& Meier, 2015, 249). Therefore, the importance of leadership styles in organizational management should vary across internal organizational settings, and followers' perceptions of leadership styles are also likely to change in such contexts.

Research on gender and leadership increasingly recognizes that the workplace significantly affects the gendered nature of the "dialectic" between men and women, which is an inevitable feature of leadership dynamics (Collinson, 2005). Leadership establishes a key part of an organization's social structure ("regular and predictable patterns of behavior") and culture ("shared beliefs, values, symbols, and goals") (Eagly \& Carli, 2007, 137). Therefore, an organizational member's idea of the ideal leader can change based on the group's gender distribution (Lemoine, Aggarwal, \& Steed, 2016). For instance, studies on gender and leadership 
styles show that the performance of female leaders is less effective in male-dominated contexts (Carli \& Eagly, 2011; Eagly \& Carli, 2007; Lyness \& Thompson, 2000). Other research suggests that changes in the proportion of women in organizations affect employees' preference for male leaders (Stoker, van der Velde, \& Lammers, 2012). These studies imply that gender representation in the workplace can cause significant impact on management and performance, by reshaping subordinate perceptions of leadership styles.

This view of leadership as a dynamic process has been constructed by the social identity theory of leadership and the related self-categorization theory. According to these theories, organizational membership can affect what employees perceive as the "characteristics of the ingroup" and how they develop "a larger group identity embodied by the prototype that is composed of the larger set of attributes, norms, and behaviors that are representative of the group as a whole" (Lemoine, Aggarwal, \& Steed, 2016, 472; Hogg, 2001; Hogg \& Terry, 2000).

In developing our hypotheses, we build our explanations on the social identity theory and related theories. We expand the discussion of employees' development of a group identity, with a focus on the role of gender, because biases in gender representation within organizations may increase the salience of gender within organizational settings (Randel, 2002). This enhanced salience due to gender composition may subsequently impact the "group prototype" to become more masculine or feminine. A group with substantially more women or more men may have different ideas of what their leaders should be like (Lemoine, Aggarwal, \& Steed, 2016, 473). Putting salience of gender in organizational settings together with the importance of employee gender, it is reasonable to claim that the prototypes of groups which are primarily composed of males are more masculine, and groups chiefly composed of females are more feminine (Lemoine, Aggarwal, \& Steed, 2016). Extending our first set of hypotheses (H1a and H1b), we argue that, 
for leadership styles characterized by clear gender differences in subordinates' perceptions, employee gender and organizational gender representation will interact to predict subordinates' perceptions toward such leadership styles.

First, our prediction of subordinates' perceptions of transformational leadership was that there would be clear gender differences. We further expect that gender representation in the workplace will reinforce this perceptional difference. Female employees, who have more positive perceptions of transformational leadership than male employees, may enhance the degree of their positive perceptions with an increase in women's representation in their workplace. Male employees, who have less positive perceptions of transformational leadership than their female counterparts, may strengthen the degree of their negative perceptions toward such leadership styles, as women become more prevalent in their organizations. On the other hand, in male-dominated settings where more masculine prototypes are developed as a group prototype, both female and male employees will share less positive perceptions of transformational leadership.

Moreover, we believe that the trend of increasing representation of women in bureaucracies and in the broader society may also play a role in shaping employees' perceptions of leadership styles (see Park \& Liang, 2019). In the case of Korea, for example, the presence of female civil servants has grown over time at all job levels. ${ }^{3}$ This suggests that female employees see more women access managerial positions, and that this will help to motivate them to seek upward mobility in their own career. In this sense, it is likely that more women will admire leaders who show an inspiring vision if they share an identity. Since improved representation of women in bureaucracies should have a more positive impact on female than male employees'

\footnotetext{
${ }^{3}$ http://www.mpm.go.kr/mpm/lawStat/infoStatistics/hrStatistics/hrStatistics03/ (accessed November 20, 2019).
} 
perceptions, it is not surprising that there is a larger gender gap in civil servants' perceptions of transformational leadership, particularly in organizations with higher representation of women. ${ }^{4}$

On the other hand, we predicted that gender differences in subordinate perceptions of transactional leadership would be difficult to distinguish. Given employee gender is likely to act as "a salient indicator of prototypicality" (Lemoine, Aggarwal, \& Steed, 2016, 473), we further expect that gender representation in the workplace will cause little impact on subordinate perceptions of transactional leadership across male and female employees. In male-dominated contexts, employees of both genders may see leadership with directive and agentic characteristics as being more pertinent (Carli \& Eagly, 2011; Eagly, Karau \& Makhijani, 1995). ${ }^{5}$ In more feminine settings, where feminine and more democratic leadership styles are proven more beneficial (Eagly, Karau \& Makhijani. 1995), characteristics of transactional leadership may still be perceived as necessary and shared by managers regardless of their gender. Therefore,

H2a: In organizations with a majority of female employees, the difference between female and male employees' perceptions of transformational leadership will be greater than in organizations with a majority of male employees.

$\boldsymbol{H} \boldsymbol{2 b}$ : In organizations with a majority of female employees, female employees will have more positive perceptions of transformational leadership than male employees.

H3: In organizational management, female and male employees' perceptions of transactional leadership do not significantly differ as women's representation in organizations changes.

\footnotetext{
${ }^{4}$ As women's representation is improved, such a gender gap exists even in top executive officers' perceptions of employees. Anecdotal evidence suggests that, while a female vice minister views more balanced gender representation as "the availability of more qualified female employees", a male vice minister admits that with a growing number of female employees, it is "not easy and sometimes cumbersome to direct female subordinates." Interviews with Lee Bok-sil and Kwon Yong-hyun, Vice Ministers of Gender Equality and Family, South Korea, April 2016.

${ }^{5}$ Although these characteristics do not precisely represent transactional leadership, they are more closely related with transactional than transformational leadership styles.
} 


\section{Research Design: A List Survey Experiment}

To examine whether public employees have different perceptions of transformational and transactional leadership according to their individual and organizational characteristics, we conducted a survey experiment of national civil service officials in Korea. We test our hypotheses using a list experiment to determine whether, in the regular operations of public sector organizations, public employees consider these leadership styles as important.

There are three important reasons for our choice of this survey design. A list experiment is a format of indirect questioning that asks respondents to disclose how many items on a list are relevant to them. This survey design is particularly useful and has been widely used when respondents are government officials, who may feel reluctant to reveal their true opinions of their superiors or political principals and thus have incentives to provide answers that conform to prevalent social norms by providing answers heavily biased in favor of their agency heads (Lee \& Park, forthcoming; Meng, Pan, \& Yang, 2017). Moreover, respondents are surveyed at their place of work, and direct questions to assess their leaders might also cause higher nonresponse rates, which in turn may lower the validity of our results. A list experiment is therefore designed in a way to address the potential methodological problems and help to obtain truthful answers to survey questions that can be challenging (Blair \& Imai, 2012; Corstange, 2009; Imai, 2011). ${ }^{6}$ Finally, our survey firm negotiated access to career civil servants, and a format of indirect questioning was more preferred to public employees as it provided a higher rate of acceptance among the public agents.

\footnotetext{
${ }^{6}$ See also recent work discussing methodological issues and possible solutions with list experiments, such as measurement error (Blair, Chou, \& Imai, 2019).
} 
The standard design for list experiments randomizes respondents into control and treatment groups where a list of control items is presented to the former group and a list of the same control items plus one treatment, or sensitive, item of interest is presented to the latter group. That is, the random assignment process gives respondents an equal chance of being in the control or the treatment group. Once assigned to either group, respondents are then asked to count the number of items on their list that apply to them. Through this design, respondents may safely reveal their truthful answers, including the sensitive item, as long as they are not choosing either none or all of the items on their list. Based on the two assumptions - 1) a sensitive item does not affect respondents' answers to control items (the no design effect assumption) and 2) respondents give truthful answers for a sensitive item (the no liars assumption), researchers may also estimate the proportion of respondents who are more likely to select the treatment item by estimating the difference in the mean response between the treatment and control groups (Blair \& Imai, 2012, pp. 51-52). ${ }^{7}$

In our study, we asked the following question to the control group: Several elements are listed below. How many of these elements do you think are important in the regular operations of your organizations? Please do not tell me which ones you agree with; only say how many elements you think are important.

(1) The level of autonomy given to your agency head in managing internal organization

(2) The level of discretion given to your agency head in managing human resources

(3) The level of flexibility given to your agency head in allocating financial resources [Items are shown in a randomized order]:

\footnotetext{
${ }^{7}$ In the appendix, we provide detailed guidance regarding the logic of list experiments.
} 
Although a leadership style is important in itself, the functioning of leadership behavior depends on context. In this sense, public leadership is specifically linked to organizational settings and capacities in the public sector. Leadership quality is related to organizational performance as well as leader attributes (Ulrich, Zenger, \& Smallwood, 1999). We, therefore, adopt the integrative approach to leadership (Ingraham, Sowa, \& Moynihan, 2004; Moynihan \& Ingraham, 2004) in choosing our control items, which argues that public leadership is exerted through "actions that build and improve organizational abilities and management systems" (Moynihan \& Ingraham, 2004, 428). Any public leaders must employ these conditions to produce significant organizational capabilities and accomplish certain levels of performance (Ingraham, Sowa, \& Moynihan, 2004).

Among the control items, autonomy in managing the internal organization relates to the organization's internal management abilities. The second control condition, discretion in managing human resources, relates to the organization's human capital. Finally, flexibility in allocating financial resources relates to the organization's financial management skills. Public leaders are typically faced with externally generated and directed management changes that likely constrain their leadership authority to some degree (Ingraham, Sowa, \& Moynihan, 2004). However, public leaders must build on these conditions in certain ways. If they are given more authority in handling each of these conditions and can combine these into broader organizational strength, the perception of their leadership capacities is likely to be more positive.

Based on previous findings and survey pretesting, we expect that the selected control items are positively correlated. The capacity to generate integrating linkages across these conditions often depends on levels of performance achieved by governments. While high performance governments tend to be able to create integrative capacity, low performance ones 
generally lack such capacity (Gill \& Meier, 2001; Moynihan \& Ingraham, 2003). One of the most distinct differences, however, is the presence and quality of leadership (Ingraham, 2001), which we now examine in organizational context through the two most prominent leadership behaviors - transformational and transactional leadership.

\section{Treatment Conditions}

In order to estimate and compare public employees' perceptions of different leadership styles, we split the sample of national civil servants into two treatment groups. The first treatment group tests the perception of transformational leadership styles in the management of public sector organizations. The second treatment group tests the perception of transactional leadership abilities in organizational management.

In the previous section, we conceptualized these leadership styles by building on the discussion of different leadership models. ${ }^{8}$ With the first treatment condition, we examine the perception of leaders' transformational behavior. The central element of transformational behavior in organizational context is leaders' ability to communicate and direct toward a vision of the organization's future. In our study, we asked the first treatment group the same question as the control group, with the exception that a treatment item relating to leaders' transformational behavior is added to the list:

Several elements are listed below. How many of these elements do you think are important in the regular operations of your organizations? Please do not tell me which ones you agree with; only say how many elements you think are important.

(1) The level of autonomy given to your agency head in managing internal organization

\footnotetext{
${ }^{8}$ The conceptualization of these leadership styles can be composed of more than one element, but focusing on the key element of each leadership behavior, which clearly distinguishes one type from the other, will help respondents to easily connect the element to their leaders' attributes.
} 
(2) The level of discretion given to your agency head in managing human resources

(3) The level of flexibility given to your agency head in allocating financial resources

(4) The ability of your agency head to direct toward a vision of the organization's future

[Items are shown in a randomized order]

With the second treatment condition, we examine the perception of leaders' transactional behavior. The main element of transactional behavior in organizational context is leaders' ability to monitor employees' performance and use rewards or punishment to adhere to procedures. For the second treatment group, the question is also identical to that of the control group, with the exception that a treatment item relating to a leader's transactional behavior is added to the list:

Several elements are listed below. How many of these elements do you think are important in the regular operations of your organizations? Please do not tell me which ones you agree with; only say how many elements you think are important.

(1) The level of autonomy given to your agency head in managing internal organization

(2) The level of discretion given to your agency head in managing human resources

(3) The level of flexibility given to your agency head in allocating financial resources

(4) The ability of your agency head to monitor performance and use incentives to follow procedures [Items are shown in a randomized order]

\section{Sampling and Balance}


Our list experiment was conducted as part of the Public Performance and Management Survey, which occurred from 2015 to $2016 .{ }^{9}$ This is an annual survey of national civil servants in Korea. ${ }^{10}$ Survey respondents are all public employees who were recruited by the Korean central government to implement policy programs made by presidents and lawmakers. Entry-level recruitment of national civil servants is made through competitive examinations at grades 5,7 , and 9 (high-low), respectively.

The sampling method for the Public Performance and Management Survey initially considered including all central government agencies of Korea. Due to the inaccessibility of certain agencies and limits on the feasibility of such broad survey implementation, our samples include public employees from 26 government agencies. ${ }^{11}$ However, the selected agencies vary in terms of their employees' individual characteristics and their gender representation, and the sample agencies are overall representative of Korean state agencies in terms of demographics. The surveys were distributed to public employees ranked at grade 4 to 9 based on a stratified sampling method using gender, civil service rank, and recruitment type. The surveys were distributed via online methods to all respondents at their place of work. ${ }^{12}$ Respondents were randomly selected into three groups and completed the surveys in private.

In total, 1,350 survey experiments were handed out, with 450 surveys for each of the three conditions. Of the 1,350 surveys distributed, 816 survey experiments were completed (60.4\%). Of the completed surveys, 199 (24.4\%) came from grade 7-9 (low), 513 (62.9\%) from

\footnotetext{
${ }^{9}$ The Public Performance and Management Survey includes 29 sets of questions concerning organizational performance and management, public sector leadership, organizational culture and commitment, as well as 10 questions about respondents' demographic and civil service characteristics.

${ }^{10}$ The human research subjects aspect of our experimental protocol was approved by our university's Institutional Review Board.

${ }^{11}$ Agencies excluded are those not accessible, such as intelligence agencies, defense and security ministries, or those that were too small to draw enough samples to be meaningfully representative of Korean agencies. See Appendix Table A1 for a list of participating agencies.

${ }^{12}$ Respondents who agreed to participate in the surveys received an email with a link that led them to the questionnaire.
} 
grade 5 or 6, and $104\left(12.7 \%\right.$ ) from grade 4 (high). ${ }^{13}$ As shown in Tables 1 and 2, the completed surveys show that $267(32.7 \%)$ came from the control group, $267(32.7 \%)$ from the first treatment group, and $282(34.6 \%)$ from the second treatment group, making the response rate for the control condition similar to the response rate for the treatment conditions.

Table 1 shows the characteristics of the respondents by group: an employee gender of 1 $=$ female, and $0=$ male; an education level of $1=$ completion of secondary education (or lower), $2=$ completion of community college, $3=$ completion of college (4-year program), $4=$ completion of graduate school (master), and $5=$ completion of graduate school (Ph.D.); a civil service rank of $1=\operatorname{grade} 9$ (lowest), $2=\operatorname{grade} 8,3=\operatorname{grade} 7,4=\operatorname{grade} 6,5=\operatorname{grade} 5$, and $6=$ grade 4 (highest); a civil service job category of $1=$ administrative, and $0=$ technical; and a recruitment type of $1=$ centralized civil service examination, and $0=$ open recruitment. Table 1 also presents the respondents' organizational characteristics by group: a proportion of female employees in organizations (org. characteristic) and whether an agency is led by a female head. The $F$-test results indicate that no characteristics differ across control and treatment groups at conventional levels of statistical significance.

[Table 1 about here]

\section{Results}

In this section, we first present the observed data and mean results by group from the list experiment to compare the perception between transformational and transactional leadership styles. Then, to assess whether perception is conditional on gender differences, as well as the

\footnotetext{
${ }^{13}$ Since higher ranking civil servants are expected to have more direct interaction with agency heads and thus more precise perceptions of agency heads' leadership styles than lower ranking employees, they are slightly oversampled in our survey.
} 
interaction between gender and women's representation in public sector organizations, we demonstrate the results using maximum likelihood estimators with a series of model specifications.

\section{Overall Perceptions of Leadership Styles}

In Table 2, we present a summary of the observed data for the control group as well as the two treatment groups. ${ }^{14}$ The left panel of Figure 1 demonstrates the mean response for each group: 2.37 items for the control group, 2.75 items for the transformational behavior treatment group, and 2.82 items for the transactional behavior treatment group. Examining all respondents based on simple $t$ tests, we see a positive and statistically significant difference in the mean responses between the two treatment groups and the control group, respectively. This suggests that civil servants have positive perceptions of both transformational and transactional leadership styles in organizational management.

[Table 2 about here]

Based on these mean responses, we further show the estimated proportion of respondents who answer our treatments affirmatively in the list experiment in the right panel of Figure 1. According to the simple estimation based on the difference in the mean response between the treatment and control groups (see Appendix Table A2 for computation), the list experiment indicates that $38.2 \%$ (with the $95 \%$ confidence interval of $[24.3,52.1]$ ) of respondents think that

\footnotetext{
${ }^{14}$ In the control group, over $50 \%$ of the respondents answer affirmatively to all three control items. Given these results, ceiling effects can be a particular concern to our analysis. We test for this possibility by conducting a statistical test proposed by Blair and Imai (2012). At $\alpha=.05$ as the significance level of the test, we find the minimum $p$ value to be bigger than .10. Since these $p$ values are above the $\alpha$ threshold, we cannot reject the null hypothesis of no ceiling effect.
} 
agency heads' transformational competencies are important in managing organizational performance, while $45.2 \%$ (with the $95 \%$ confidence interval of $[31.3,59.1]$ ) of respondents think that agency heads' transactional abilities are important in maintaining organizational performance. This demonstrates that, on average, public employees' perceptions toward transformational and transactional behavior are similar. More than $38 \%$ of public employees consider the integration of either leadership style with organizational conditions as important in the routine operations of their organizations. This similarity in the degree of perceptions toward transformational and transactional behavior may not come as a surprise, given that both leadership styles play a role in organizational management. In the next section, we progress to analysis of civil servants' perceptions of leadership by highlighting their gender and gender representation in the workplace in order to examine how these individual and organizational aspects are associated with either leadership style.

[Figure 1 about here]

\section{Difference in Leadership Perceptions by Gender}

To assess whether the civil servants' perception of leadership styles is conditional on their gender, we use a maximum likelihood estimator adopted by Blair and Imai (2012). Being able to run a multivariate regression analysis is critical, because scholars are often interested in knowing how the likelihood of answering the sensitive question affirmatively changes with respondents' characteristics as well as estimating the population proportion of such respondents (Imai, 2011). Statistical efficiency is a particularly important concern for the list experiment design as indirect questioning means a loss of information (Blair \& Imai, 2012). Maximum likelihood estimators 
for efficient multivariate statistical analysis are particularly useful, because the proportion of respondents answering affirmatively to the sensitive item can be estimated under certain assumptions (i.e. no design effect and no liars assumptions) by merely computing the difference in the mean response between the treatment and control groups that are randomly selected (see Blair \& Imai, 2012).

In Table 3, we demonstrate the estimated coefficients and their standard errors from the fitted binomial logistic regression model where the dependent variables are: whether or not transformational leadership is considered important to respondents in organizational management (Model 1) and whether or not transactional leadership is considered important to respondents in organizational management (Model 2). In Model 3, the dependent variable is not straightforward due to a two-step procedure necessary for computation (Imai, 2011). ${ }^{15}$ Intuitively, the two treatment groups and one control group are analyzed simultaneously, and the treatment effects are estimated through the difference in the mean response between the treatment and control groups based on the coefficients generated from the fitted binomial logistic regression model (i.e., maximum likelihood estimators).

The two independent variables of our study are civil servants' gender measured as a binary variable and women's representation in their organizations measured as a proportion (org. characteristic). ${ }^{16}$ We also control for the characteristics of the respondents such as age, level of education, civil service rank, job category, recruitment type, and private sector experience, as well as the respondents' organizational characteristics such as whether an agency head is female.

\footnotetext{
${ }^{15}$ For computation, a nonlinear regression model is first fitted to the control group, and then the other nonlinear regression model is fitted to the treatment group using the adjusted response variable (Blair \& Imai, 2012, p. 53).

${ }^{16}$ Information about the proportion of female employees across civil service ranks within each organization is, unfortunately, not available due to data limitation, as the Korean government has not made such information publicly available yet.
} 
[Table 3 about here]

Figure 2 demonstrates the results of the difference in estimated proportions of female and male respondents answering our treatments affirmatively. The figure shows, for each treatment, the estimated proportion of female civil servants answering affirmatively minus the estimated proportion of male civil servants responding affirmatively. Positive estimates indicate female public employees have more positive perceptions toward the treatment, and negative estimates indicate male public employees have more positive perceptions toward the treatment. Examining the two treatments, we see a positive difference in estimated proportions for the transformational leadership treatments, which suggests female civil servants have more positive perceptions toward transformational leadership than male employees. This finding strongly supports Hypothesis 1a. However, we see a difference in estimated proportions for the transactional leadership treatments not statistically significant, suggesting female and male employees' perceptions toward transactional leadership are not distinguished. This finding is in line with our expectation related to Hypothesis $1 b$. In the next section, we look into the organizational effect through an interplay with employee gender.

[Figure 2 about here]

\section{Moderating Role of Organizational Context: Gender Representation in the Public Sector}

In this section, we further assess whether gender representation in the respondents' organizations shapes their perception of leadership styles through an interplay with the respondents' gender. In Table 4, we show the estimated coefficients and their standard errors from the fitted binomial 
logistic regression model where all the variables are the same included in Table 3, except an interaction variable between employee gender and women's representation in public sector organizations. ${ }^{17}$ Table 4 demonstrates whether perception is conditional on the interaction between employee gender and women's representation in public sector organizations, controlling for the individual and organizational characteristics of the respondents. Again, the two treatment groups and one control group are analyzed simultaneously, and the treatment effects are estimated through the difference in the mean response between the treatment and control groups based on the maximum likelihood estimators.

[Table 4 about here]

Since we examine the effect of the interplay between the respondents' gender and women's representation in their organizations, we compare the mean response of female and male respondents across varying proportions of female employees in our 26 sample agencies. Women's representation in Korea's civil service has increased over time and has now reached a half of the civil service population (50.2\%) as of $2017 .{ }^{18}$ Yet, in the upper ranks (grade 5 or higher), the proportion of female employees is only about $20 \% .{ }^{19}$ Women's representation also varies significantly across agencies. As shown in Appendix Table A1, among 26 agencies participating in our survey, it ranges between $18.6 \%$ and $56.9 \%$. However, there are only four agencies where women are in the majority. Given these facts, we divide our sample agencies into three groups according to gender representation in the organizations: 1 ) the lowest $33^{\text {rd }}$ percentile

\footnotetext{
${ }^{17}$ This model is compatible with cross-level interactions as evidenced by past experimental research (see Blair \& Imai, 2012, pp. 58-60). See also https://cran.r-project.org/web/packages/list/list.pdf (accessed November 20, 2019).

${ }^{18} \mathrm{http}: / /$ www.mpm.go.kr/mpm/lawStat/infoStatistics/hrStatistics/hrStatistics03/ (accessed November 20, 2019).

19 https://www.yna.co.kr/view/AKR20180628083300001 (accessed November 20, 2019).
} 
(women's representation between $18.6 \%$ and $31.3 \%$ ), 2) a mid-range (women's representation between $31.7 \%$ and $43.1 \%$ ), and 3 ) the highest $33^{\text {rd }}$ percentile (women's representation between $43.2 \%$ and $56.9 \%$ ). Figure 3 demonstrates the results of the difference in estimated proportions of female and male respondents answering our treatments affirmatively across different organizational contexts. The figure shows, for each treatment and organizational context, the estimated proportion of female respondents answering affirmatively minus the estimated proportion of male respondents answering affirmatively. Positive estimates indicate female respondents have more positive perceptions toward the treatment, and negative estimates indicate male respondents have more positive perceptions toward the treatment.

[Figure 3 about here]

Examining the treatments across organizational contexts, in Figure 3.1, we see a positive and statistically significant difference in estimated proportions for the transformational leadership treatments only in organizations where women's representation is sufficiently high. In other words, female employees have more positive perceptions of transformational leadership behavior than male employees in organizations where the proportion of female employees is at least $32 \%$ or higher. However, the difference is not statistically significant in male-dominated organizations where women's representation is below $31 \%$. The results are largely in line with our predictions concerning Hypotheses $2 a$ and $2 b$.

In the case of the transactional leadership treatments, as shown in Figure 3.2, the difference is not statistically significant across various organizational settings. As stated in Hypothesis 3, female and male employees tend to have similar perceptions of transactional 
leadership behavior, and this does not change with women's representation in organizations. Overall, the interaction between the respondents' gender and gender representation in their workplace produces more nuanced and distinct outcomes in analyzing public employees' perceptions of prominent leadership behaviors in organizational management and performance.

In addition, some of the estimated coefficients for our control variables in Table 4 are worth mentioning. The results suggest that more educated employees have more positive perceptions of transformational leadership behavior than less educated ones, whereas higher ranking civil servants have more positive perceptions of transactional leadership behavior than lower ranking ones. We also find that, under female agency heads, female employees tend to have more positive perceptions of both leadership styles than male employees, but the gender gap in perceptions ( 0.202 for transformational and 0.061 for transactional) was not statistically significant.

\section{Discussion}

In this article, we seek to broaden our understanding of public leadership styles by focusing on the role of gender in public sector organizations. We do so by examining how subordinate gender affects the perceived importance of transformational and transactional leadership styles and how the extent to which the organizational context is gendered reshapes employees' perceptions. For these analyses, we developed an original experiment design using a survey technique based on indirect questioning and employed statistical methods to estimate coefficients of interest from this survey experiment. We find that there is a clear gender gap in followers' perceptions of particular leadership styles, and these gender differences are moderated by the representation of female employees in organizations. Confirming our predictions, female employees have more 
positive perceptions of transformational leadership behaviors than male employees, but female and male employees' perceptions of transactional leadership behaviors are not significantly different. When interacting with organizational characteristics, the gender gap in followers' perceptions of leadership styles becomes more distinct. An increase in women's representation in public sector organizations leads to more positive perceptions of transformational leadership behaviors among female than male employees. However, changes in bureaucratic gender representation do not affect perceptions of transactional leadership behaviors, which were similar among female and male employees.

These findings have important implications for public management practice. Extending evidence of more positive relationships between leaders and employees in same-gender dyads, we show that gendered conditions at the organizational level may also affect leader-employee relationships. Our findings suggest that transformational leadership should be considered more powerful in organizations with more female employees. Although male-dominated organizations see no significant gender gap in perceptions of leadership styles, the masculine nature of their work environment might be more conducive to transactional leadership. More broadly, given the patterns of increasing women's representation in both public and private sectors in Korean society, it is important, for management and performance purposes, to have superiors who share an identity with female employees who now have stronger career ambition. Our findings corroborate that female employees indeed perceive leaders' capacity to show an inspiring vision as more important than do male employees, and that such perception is reinforced in the workplace, where they are surrounded by colleagues of the same gender who may have a similar spirit. 
Although we endeavor to make our experimental design robust, there are some alternative explanations for our findings on a gender gap in followers' perceptions of leadership styles. First, they may be due to the types of relationships followers formulate with their agency heads. Existing research on public management suggests that when public employees are in same-gender dyads and experience longer tenure with their superiors, they tend to build positive relationships with the superiors (Hassan \& Hatmaker, 2015). If there is a systematic association between the pattern of building leader-member relationships and a follower's gender and tenure, the types of relationships formed with their agency heads may affect the employees' perceptions of leadership. Second, it is also possible that employees consider certain leadership styles to be more important, not only because they think positively of their leaders having such styles, but also because the leaders actually lack the styles which, however, are perceived to be necessary for their organization. Additional analyses assessing incumbent agency heads' leadership will help to clarify a more precise causal mechanism in this context.

\section{Conclusion}

Our finding that followers' perceptions may depend on characteristics of the organization to which they belong offers a strong foundation for future research agenda. First, scholars can expand the scope of research on gender differences in followers' perceptions regarding leadership styles by examining other features of the organization that are related to gender representation in public sector organizations. In male-dominated organizations, an authority structure may be more hierarchical and with weak upward communication. In contrast, an authority structure may be more lateral and the upward communication can be stronger in female-dominated organizations. Public sector organizations are found to exhibit low levels of 
reported transformational leadership behaviors when they are more formalized and their authority structure is more hierarchical (Wright \& Pandey, 2010). Yet, there should be wide variation in the degrees of organizational formalization and the hierarchical structure of authority across agencies within a country as well as across countries.

The strict civil service culture in Korea, for example, is implicitly embraced within traditional Asian values or Confucianism (Lee \& Schuler, 2019). However, the trend of increasing representation of women in the public sector might weaken this culture. It would be interesting to examine whether, and if so how, organizational culture has changed in agencies with higher representation of female employees versus more male-dominated agencies. More broadly, civil service culture may differ in the Western world where egalitarianism tends to be highly valued. If the cultural characteristics of countries play a role in shaping civil servants' perceptions, we might see a smaller gender gap in followers' perceptions of leadership behaviors in the Western organizations. Last but not least, as the results of some of our control variables show, a specific style of public leadership can be linked with other characteristics of followers and organizational contexts, such as civil service rank, job category, and the representation of diverse minority groups, and further research is necessary to look into their effects.

\section{References}

Alimo-Metcalfe, Beverly. 1995. An investigation of female and male constructs of leadership and empowerment. Women in Management Review 10: 3-8.

Andrews, Rhys, and George A. Boyne. 2010. Capacity, leadership, and organizational performance: Testing the black box model of public management. Public Administration Review 70: 443-54.

Atchison, Amy, and Ian Down. 2009. Women cabinet ministers and female-friendly social policy. Poverty \& Public Policy 1: 1-23. 
Bass, Bernard M. 1985. Leadership and performance beyond expectations. New York: Free Press.

Bass, Bernard M., Bruce J. Avolio, and Leanne Atwater. 1996. The transformational and transactional leadership of men and women. Applied Psychology 45: 5-34.

Bass, Bernard M., Bruse J. Avolio, Dong I. Jung, and Yair Berson. 2003. Predicting unit performance by assessing transformational and transactional leadership. Journal of Applied Psychology 88: 207-18.

Bass, Bernard M., and Ronald E. Riggio. 2006. Transformational leadership. Mahwah, NJ: Lawrence Erlbaum.

Bellé, Nicola. 2014. Leading to make a difference: A field experiment on the performance effects of transformational leadership, perceived social impact, and public service motivation. Journal of Public Administration Research and Theory 24: 109-136.

Blair, Graeme, Winston Chou, and Kosuke Imai. 2019. "List experiments with measurement error." Political Analysis 27: 455-480.

Blair, Graeme, and Kosuke Imai. 2012. Statistical analysis of list experiments. Political Analysis 20: 47-77.

Bligh, Michelle C. 2011. Followership and follower-centered approaches. In The sage handbook of leadership, ed. Alan Bryman, David Collinson, Keith Grint, Mary Uhl-Bien, and Brad Jackson, 425-436. London: SAGE.

Bligh, Michelle C., Jeffrey C. Kohles, Craig L. Pearce, Joseph E. Justin, and John F. Stovall. 2007. When the romance is over: Follower perspectives of aversive leadership. Applied Psychology 56: 528-557.

Burns, James MacGregor. 1978. Leadership. New York: Harper \& Row.

Bycio, Peter, Rick D. Hackett, and Joyce S. Allen. 1995. Further assessments of Bass's (1985) conceptualization of transactional and transformational leadership. Journal of Applied Psychology 80: 468-478.

Campbell, Andrea Louise. 2002. Self-interest, social security, and the distinctive participation patterns of senior citizens. American Political Science Review 96: 565-574.

Carli, Linda L., and Alice H. Eagly. 2011. Gender and leadership. In The sage handbook of leadership, ed. Alan Bryman, David Collinson, Keith Grint, Mary Uhl-Bien, and Brad Jackson, 103-117. London: SAGE. 
Collins, Brian J., Carla J. Burrus, and Rustin D. Meyer. 2014. Gender differences in the impact of leadership styles on subordinate embeddedness and job satisfaction. The Leadership Quarterly 25: 660-671.

Collinson, David L. 2005. Dialectics of leadership. Human Relations 58: 1419-1442.

Corstange, Daniel. 2009. Sensitive questions, truthful answers? Modeling the list experiment with LISTIT. Political Analysis 17: 45-63.

Dvir, Taly, Dov Eden, Bruce J. Avolio, and Boas Shamir. 2002. Impact of transformational leadership on follower development and performance: A field experiment. Academy of Management Journal 45: 735-744.

Eagly, Alice H., and Linda L. Carli. 2007. Through the labyrinth: The truth about how women become leaders. Cambridge, MA: Harvard Business School Press.

Eagly, Alice H., and Madeline E. Heilman. 2016. Gender and leadership: Introduction to the special issue. The Leadership Quarterly 3: 349-353.

Eagly, Alice H., Mary C. Johannesen-Schmidt, and Marloes L. van Engen. 2003. Transformational, transactional, and laissez-faire leadership styles: A meta-analysis comparing women and men. Psychological Bulletin 129: 569-591.

Eagly, Alice H., Steven J. Karau, and Mona G. Makhijani. 1995. Gender and the effectiveness of leaders: A meta-analysis. Psychological Bulletin 117: 125-145.

van Engen, Marloes L., and Tineke M. Willemsen. 2004. Sex and leadership styles: A metaanalysis of research published in the 1990s. Psychological Reports 94: 3-18.

Felfe, Jörg, and Birgit Schyns. 2006. Personality and the perception of transformational leadership: The impact of extraversion, neuroticism, personal need for structure, and occupational self-efficacy. Journal of Applied Social Psychology 36: 708-739.

Fernandez, Sergio. 2005. Developing and testing an integrative model of public sector leadership: Evidence from public education arena. Journal of Public Administration Research and Theory 15: 197-217.

George, Bert, Steven Van de Walle, and Gerhard Hammerschmid. 2019. Institutions or Contingencies? A Cross-Country Analysis of Management Tool Use by Public Sector Executives. Public Administration Review 79: 330-342.

Gill, Jeff, and Kenneth J. Meier. 2001. Ralph's pretty-good grocery versus Ralph's super market: Separating excellent agencies from the good ones. Public Administration Review 61: 9-17. 
Goldberg, Caren B., Christine Riordan, and Bryan S. Schaffer. 2010. Does social identity theory underlie relational demography? A test of the moderating effects of self-continuity and status-enhancement on similarity effects. Human Relations 63: 903-26.

Goldberg, Caren B., Christine Riordan, and Lu Zhang. 2008. Relational demography and leadership perceptions: Is similar always better? Group and Organization Management 33: $330-55$.

Grant, Adam M. 2012. Leading with meaning: Beneficiary contact, prosocial impact, and the performance effects of transformational leadership. Academy of Management Journal 55: $458-76$.

Grissom, Jason A., Jill Nicholson-Crotty, and Lael Keiser. 2012. Does my boss's gender matter? Explaining job satisfaction and employee turnover in the public sector. Journal of Public Administration Research and Theory 22: 649-73.

Hassan, Shahidul, and Deneen M. Hatmaker. 2015. Leadership and performance of public employees: Effects of the quality and characteristics of manager-employee relationships. Journal of Public Administration Research and Theory 25: 1127-1155.

Hogg, Michael A. 2001. A social identity theory of leadership. Personality and Social Psychology Review 5: 184-200.

Hogg, Michael A., and Deborah I. Terry. 2000. Social identity and self-categorization processes in organizational contexts. Academy of Management Review 25: 121-140.

Hunter, Samuel T., Katrina E. Bedell-Avers, and Michael D. Mumford. 2007. The typical leadership study: Assumptions, implications, and potential remedies. The Leadership Quarterly 18: 435-446.

Imai, Kosuke. 2011. Multivariate regression analysis for the item count technique. Journal of the American Statistical Association 106: 407-416.

Ingraham, Patricia W. 2001. Linking leadership to performance in public organizations. Paris: Organization for Economic Co-Operation and Development.

Ingraham, Patricia W., Jessica E. Sowa, and Donald P. Moynihan. 2004. Linking dimensions of public sector leadership to performance. In The art of governance: Analyzing management and administration, ed. Patricia W. Ingraham and Laurence E. Lynn Jr., 152-170. Washington, DC: Georgetown University Press.

Jacobsen, Christian Bøtcher, and Lotte Bøgh Andersen. 2017. Leading public service organizations: How to obtain high employee self-efficacy and organizational performance. Public Management Review 19: 253-273. 
Janus, Alexander L. 2010. The influence of social desirability pressures on expressed immigration attitudes. Social Science Quarterly 91: 928-946.

Jensen, Ulrich Thy, Lotte Bøgh Andersen, Louise Ladegaard Bro, Anne Bøllingtoft, Tine Louise Mundbjerg Eriksen, Ann-Louise Holten, Christian Bøtcher Jacobsen, Jacob Ladenburg, Poul Aaes Nielsen, Heidi Houlberg Salomonsen, Niels Westergård-Nielsen, and Allan würtz. 2016. Conceptualizing and measuring transformational and transactional leadership. Administration \& Society 0095399716667157.

Keiser, Lael, Vicky M. Wilkins, Kenneth J. Meier, and Catherine A. Holland. 2002. Lipstick and logarithms: Gender, institutional context, and representative bureaucracy. American Political Science Review 96: 553-564.

Kim, Min Young, and Sung Min Park. 2017. Antecedents and outcomes of acceptance of performance appraisal system in Korean non-profit organizations. Public Management Review 19: 479-500.

van Knippenberg, Daan, Barbara Van Knippenberg, David de Cremer, and Michael A. Hogg. 2004. Leadership, self, and identity: A review and research agenda. The Leadership Quarterly 15: 825-856.

Lee, Don S. 2018. Portfolio Allocation as the President's Calculations: Loyalty, Copartisanship, and Political Context in South Korea. Journal of East Asian Studies 18: 345-365.

- 2020. Executive control of bureaucracy and presidential cabinet appointments in East Asian democracies. Regulation \& Governance 14: 82-101.

Lee, Don S., and Soonae Park. 2018. "Democratization and Women's Representation in Presidential Cabinets." Asian Journal of Political Science 26: 161-180.

forthcoming. Ministerial Leadership and Endorsement of Bureaucrats: Evidence from a Survey Experiment in Presidential Governments. Public Administration Review

Lee, Don S., and Paul Schuler. 2019. Testing the "China Model” of Meritocratic Promotions: Do Democracies Reward Less Competent Ministers Than Autocracies? Comparative Political Studies https://doi.org/10.1177/0010414019858962.

Lemoine, G. James, Ishani Aggarwal, and Laurens Bujold Steed. 2016. When women emerge as leaders: Effects of extraversion and gender composition in groups. The Leadership Quarterly 27: 470-486.

Lowe, Kevin B., K. Galen Kroeck, and Nagaraj Sivasubramaniam. 1996. Effectiveness correlates of transformational and transactional leadership: A meta-analytic review of the MLQ literature. Leadership Quarterly 7: 385-425. 
Luu, Trong Tuan. 2019. Service-oriented high-performance work systems and service-oriented behaviours in public organizations: The mediating role of work engagement. Public Management Review 21: 789-816.

Lyness, Karen S., and Donna E. Thompson. 2000. Climbing the corporate ladder: Do female and male executives follow the same route? Journal of Applied Psychology 85: 86-101.

Mary, Nancy L. 2005. Transformational leadership in human service organizations. Administration in Social Work 29: 105-118.

Meier, Kenneth J., and Jill Nicholson-Crotty. 2006. Gender, representative bureaucracy, and law enforcement: The case of sexual assault. Public Administration Review 66: 850-860.

Meier, Kenneth J., and Lawrence J. O'Toole, Jr. 2002. Public management and organizational performance: The effect of managerial quality. Journal of Policy Analysis and Management 21: 629-643.

Meindl, James R. 1993. Reinventing leadership: A radical, social psychological approach. In Social psychology in organizations: Advances in theory and research, ed. John Keith Murnighan, 89-118. Englewood Cliffs, NJ: Prentice Hall.

1995. The romance of leadership as a follower-centric theory: A social constructionist approach. The Leadership Quarterly 6: 329-341.

Meng, Tianguang, Jennifer Pan, and Ping Yang. 2017. Conditional receptivity to citizen participation: Evidence from a survey experiment in China. Comparative Political Studies 50: 399-433.

Moynihan, Donald P., and Patricia W. Ingraham. 2003. Look for the silver lining: Managing for results in state government. Journal of Public Administration Research and Theory 13: 469490.

- 2004. Integrative leadership in the public sector: A model of performance-information use. Administration \& Society 36: 427-453.

Moynihan, Donald P., Sanjay K. Pandey, and Bradley E. Wright. 2012. Setting the table: How transformational leadership fosters performance information use. Journal of Public Administration Research and Theory 22: 143-164.

O'Toole Jr., Laurence J., and Kenneth J. Meier. 2015. Public management, context, and performance: In quest of a more general theory. Journal of Public Administration Research and Theory 25: 237-256.

Paarlberg, Laurie E., and Bob Lavigna. 2010. Transformational leadership and public service motivation: Driving individual and organizational performance. Public Administration Review 70: 710-718. 
Park, Sung Min, and Hal G. Rainey. 2008. Leadership and public service motivation in U.S. federal agencies. International Public Management Journal 11: 109-42.

Rainey, Hal G. 2009. Understanding and managing public organizations. San Francisco, CA: John Wiley \& Sons.

Riggio, Ronald E., Ira Chaleff, and Jean Lipman-Blumen, eds. 2008. The art of followership: How great followers create great leaders and organizations. San Francisco, CA: JosseyBass.

Rowold, J., and A. Rohmann. 2009. Transformational and transactional leadership styles, followers' positive and negative emotions, and performance in German nonprofit orchestras. Nonprofit Management \& Leadership 20: 41-59.

Schneider, Benjamin. 1998. There IS some there there. In Leadership: The multiple-level approaches-Part B: Contemporary and alternative, ed. F. Dansereau, and F. J. Yammarino, 311-319. Stamford, CT: JAI Press.

Schyns, Birgit, and Michelle C. Bligh. 2007. Introduction to the special issue on the romance of leadership - In memory of James R. Meindl. Applied Psychology 56: 501-504.

Schyns, Birgit, and Karin Sanders. 2007. In the eyes of the beholder: Personality and the perception of leadership. Journal of Applied Social Psychology 37: 2345-2363.

Shamir, Boas, Rajnandini Pillai, Michelle C. Bligh, and Mary Uhl-Bien eds. 2007. Followercentered perspectives on leadership: A tribute to the memory of James $R$. Meindl. Greenwich, CT: Information Age Publishing.

Shamir, Boas, Eliav Zakay, Esther Breinin, and Micha Popper. 1998. Correlates of charismatic leader behavior in military units: Subordinates' attitudes, unit characteristics, and superiors' appraisals of leader performance. Academy of Management Journal 41: 387-409.

Sosik, John J., Bruce J. Avolio, and Surinder S. Kahai. 1997. Effects of leadership style and anonymity on group potency and effectiveness in a group decision support system environment. Journal of Applied Psychology 82: 89-103.

Stoker, Janka I., Mandy Van der Velde, and Joris Lammers. 2012. Factors relating to managerial stereotypes: The role of gender of the employee and the manager and management gender ratio. Journal of Business and Psychology 27: 31-42.

Trottier, Tracey, Montgomery van Wart, and XiaoHu Wang. 2008. Examining the nature and significance of leadership in government organizations. Public Administration Review 68: 319-333. 
True, Jacqui, and Michael Mintrom. 2001. Transnational networks and policy diffusion: The case of gender mainstreaming. International Studies Quarterly 45: 27-57.

Uhl-Bien, Mary, and Rajnandini Pillai. 2007. The romance of leadership and the social construction of followership. In Follower-centered perspectives on leadership: A tribute to the memory of James R. Meindl, ed. Boas Shamir, Rajnandini Pillai, Michelle C. Bligh, and Mary Uhl-Bien, 187-210. Greenwich, CT: Information Age Publishing.

Ulrich, Dave, Jack Zenger, and Norm Smallwood. 1999. Results-based leadership: How leaders build the business and improve the bottom line. Boston, MA: Harvard Business School Press.

Vigoda-Gadot, Eran, and Itai Beeri. 2012. Change-oriented organizational citizenship behavior in public administration: The power of leadership and the cost of organizational politics. Journal of Public Administration Research and Theory 22: 573-596.

Vogel, Rick, and Doris Masal. 2015. Public leadership: A review of the literature and framework for future research. Public Management Review 17: 1165-1189.

Waldman, David A., Gabriel G. Ramirez, Robert J. House, and Phanish Puranam. 2001. Does leadership matter? CEO leadership attributes and profitability under conditions of perceived environmental uncertainty. Academy of Management Journal 44: 134-160.

van Wart, Montgomery. 2003. Public sector leadership theory: An assessment. Public Administration Review 63: 214-228.

2013. Administrative leadership theory: A reassessment after 10 years. Public Administration 91: 521-543.

Watson, David, Brock Hubbard, and David Wiese. 2000. Self-other agreement in personality and affectivity: The role of acquaintanceship, trait visibility, and assumed similarity. Journal of Personality and Social Psychology 78: 546-558.

Wilkins, Vicky M., and Lael R. Keiser. 2006. Linking passive and active representation by gender: The case of child support agencies. Journal of Public Administration Research and Theory 16: 87-102.

Wright, Bradley E., and Sanjay K. Pandey. 2010. Transformational leadership in the public sector: Does structure matter? Journal of Public Administration Research and Theory 20: 75-89.

Yukl, Gary R. 2008. How leaders influence organizational effectiveness. The Leadership Quarterly 19: 708-22. 


\section{Tables and Figures}

Table 1. Characteristics of Respondents by Group

\begin{tabular}{|c|c|c|c|c|}
\hline & \multirow[t]{2}{*}{ Control } & \multicolumn{2}{|c|}{ Treatment } & \multirow[b]{2}{*}{$F$ Test } \\
\hline & & $\begin{array}{l}\text { Transformational } \\
\text { Leadership }\end{array}$ & $\begin{array}{c}\text { Transactional } \\
\text { Leadership }\end{array}$ & \\
\hline Female employee & 19.9 & 22.1 & 26.6 & $1.84(0.16)$ \\
\hline Age (years) & 42.5 & 42.1 & 41.6 & $0.99(0.37)$ \\
\hline Education (5-point scale) & 3.31 & 3.28 & 3.21 & $1.93(0.15)$ \\
\hline Rank (6-point scale) & 4.42 & 4.32 & 4.33 & $0.53(0.59)$ \\
\hline Job Category & 0.79 & 0.82 & 0.85 & $2.18(0.11)$ \\
\hline Recruitment Type & 0.85 & 0.87 & 0.90 & $1.87(0.15)$ \\
\hline Private Sector & & & & \\
\hline Experience (years) & 0.58 & 0.64 & 0.61 & $0.05(0.95)$ \\
\hline $\begin{array}{l}\text { Org. Characteristic } \\
\text { (\% of female employees }\end{array}$ & & & & \\
\hline in agencies) & 36.4 & 36.3 & 37.2 & $0.51(0.60)$ \\
\hline Female agency head & 0.07 & 0.07 & 0.09 & $0.20(0.82)$ \\
\hline $\mathrm{N}$ & 267 & 267 & 282 & \\
\hline
\end{tabular}

Table 2. Observed Data from the List Experiment

\begin{tabular}{ccccccc}
\hline & \multicolumn{2}{c}{ Control Group } & \multicolumn{4}{c}{ Treatment Groups } \\
\cline { 3 - 7 } Response & & & \multicolumn{2}{c}{$\begin{array}{c}\text { Transformational } \\
\text { Leadership }\end{array}$} & \multicolumn{2}{c}{$\begin{array}{c}\text { Transactional } \\
\text { Leadership }\end{array}$} \\
\cline { 3 - 7 } value & Frequency & Proportion & Frequency & Proportion & Frequency & Proportion \\
\hline 0 & 10 & $3.75 \%$ & 1 & $0.37 \%$ & 3 & $1.06 \%$ \\
1 & 28 & $10.49 \%$ & 11 & $4.12 \%$ & 9 & $3.19 \%$ \\
2 & 83 & $31.09 \%$ & 91 & $34.08 \%$ & 84 & $29.79 \%$ \\
3 & 146 & $54.68 \%$ & 115 & $43.07 \%$ & 126 & $44.68 \%$ \\
4 & & & 49 & $18.35 \%$ & 60 & $21.28 \%$ \\
Total & 267 & & 267 & & 282 & \\
\hline
\end{tabular}

Note: The table displays the number of respondents for each response value and its proportion for the control group and the two treatment groups. 
Figure 1. Mean Response to Control and Treatment Items (Left Panel). Estimated Proportions of Respondents Answering Treatment Items Affirmatively (Right Panel).
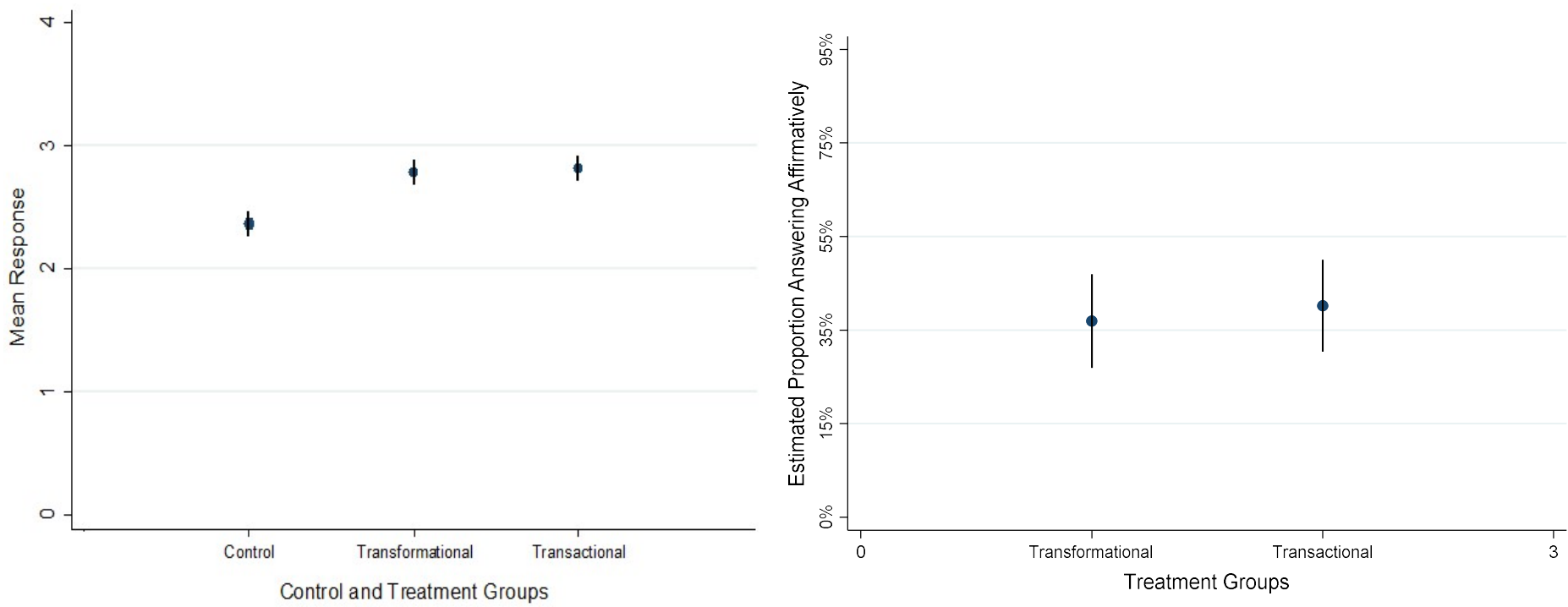

Note: $95 \%$ confidence intervals are shown. 
Table 3. Maximum Likelihood Estimator for the Effect of Gender on Leadership Perception

\begin{tabular}{lcccccc}
\hline & \multicolumn{2}{c}{ Model 1 } & \multicolumn{2}{c}{ Model 2 } & \multicolumn{2}{c}{ Model 3 } \\
\cline { 2 - 7 } & \multicolumn{2}{c}{$\begin{array}{c}\text { Treatment I: } \\
\text { Transformational }\end{array}$} & \multicolumn{2}{c}{$\begin{array}{c}\text { Treatment II: } \\
\text { Transactional }\end{array}$} & \multicolumn{2}{c}{ Control Group } \\
\cline { 2 - 7 } & Est. & S.E. & Est. & S.E. & Est. & S.E. \\
\hline Female employee & 10.753 & 8.068 & 0.852 & 0.636 & -0.422 & 0.144 \\
Org. Characteristic & & & & & & \\
(\% of female employees in & & & & & & \\
agencies) & -24.397 & 8.684 & -0.163 & 2.133 & 0.565 & 0.562 \\
Female agency head & -0.920 & 1.474 & -1.200 & 0.932 & 0.443 & 0.245 \\
Age & -0.110 & 0.074 & -0.027 & 0.035 & 0.015 & 0.009 \\
Education & 2.949 & 2.071 & 0.105 & 0.456 & 0.025 & 0.115 \\
Rank & 0.027 & 0.321 & 0.888 & 0.279 & -0.143 & 0.055 \\
Job Category & -0.137 & 0.848 & -1.401 & 0.693 & -0.006 & 0.153 \\
Recruitment Type & 0.084 & 1.219 & 0.432 & 0.844 & 0.008 & 0.182 \\
Private Sector Experience & -0.150 & 0.256 & 0.174 & 0.157 & 0.030 & 0.037 \\
Intercept & 1.719 & 3.900 & -2.809 & 2.506 & 1.094 & 0.596 \\
\hline
\end{tabular}

Note: Estimated coefficients are based on a maximum likelihood estimator where the dependent variables are whether or not transformational leadership is considered important to respondents in organizational management (Model 1) and whether or not transactional leadership is considered important to respondents in organizational management (Model 2). 
Figure 2. Difference in Estimated Proportions of Female and Male Civil Servants Answering the Treatment Items Affirmatively

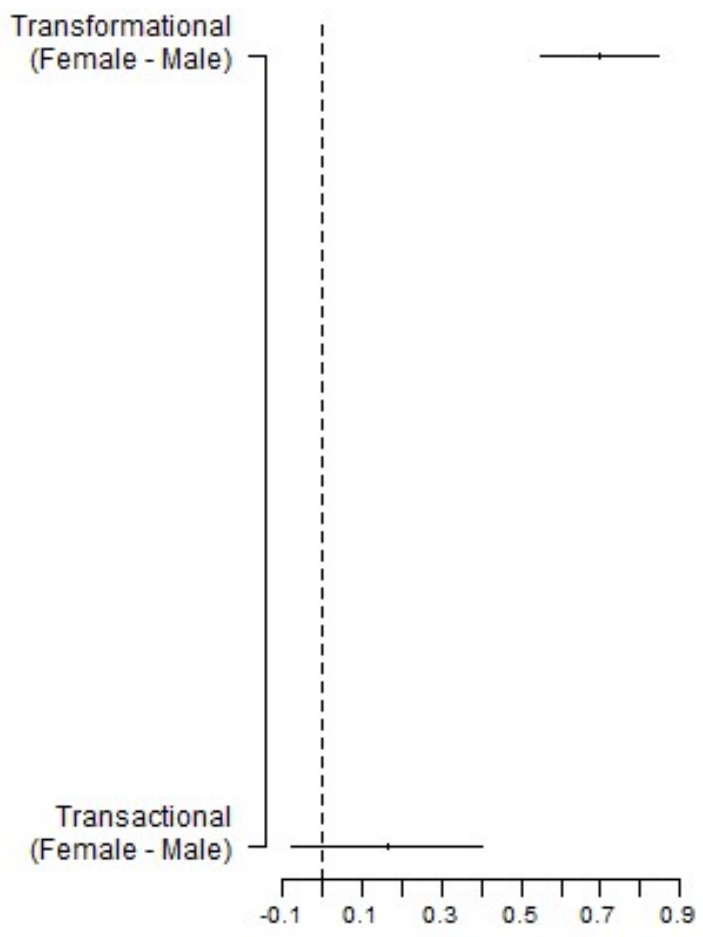

Note: $95 \%$ confidence intervals are shown. 
Table 4. Maximum Likelihood Estimator for the Effect of the Interaction between Employee Gender and Women's Representation in organizations on Leadership Perception

\begin{tabular}{|c|c|c|c|c|c|c|}
\hline & \multirow{2}{*}{\multicolumn{2}{|c|}{$\begin{array}{c}\text { Model 1 } \\
\text { Treatment I: } \\
\text { Transformational }\end{array}$}} & \multirow{2}{*}{\multicolumn{2}{|c|}{$\begin{array}{c}\text { Model 2 } \\
\text { Treatment II: } \\
\text { Transactional }\end{array}$}} & \multicolumn{2}{|c|}{ Model 3} \\
\hline & & & & & Contrc & Group \\
\hline & Est. & S.E. & Est. & S.E. & Est. & S.E. \\
\hline Female employee & -7.852 & 3.522 & 1.823 & 1.741 & -0.322 & 0.502 \\
\hline $\begin{array}{l}\text { Org. Characteristic } \\
\text { (\% of female employees in } \\
\text { agencies) }\end{array}$ & -26.538 & 9.606 & 0.605 & 2.460 & 0.441 & 0.700 \\
\hline Female employee $\mathrm{x}$ & & & & & & \\
\hline Org. Characteristic & 29.304 & 10.584 & -3.972 & 4.423 & 0.451 & 1.283 \\
\hline Female agency head & -1.162 & 1.214 & -1.145 & 0.912 & 0.513 & 0.253 \\
\hline Age & -0.040 & 0.063 & -0.019 & 0.035 & 0.012 & 0.010 \\
\hline Education & 2.628 & 1.344 & 0.121 & 0.441 & 0.018 & 0.110 \\
\hline Rank & -0.027 & 0.299 & 0.860 & 0.274 & -0.145 & 0.061 \\
\hline Job Category & 0.246 & 0.874 & -1.581 & 0.698 & 0.030 & 0.159 \\
\hline Recruitment Type & -1.476 & 1.224 & 0.299 & 0.851 & 0.149 & 0.198 \\
\hline Private Sector Experience & -0.241 & 0.209 & 0.181 & 0.152 & 0.044 & 0.041 \\
\hline Intercept & 2.013 & 3.584 & -3.071 & 2.526 & 1.106 & 0.622 \\
\hline
\end{tabular}


Figure 3. Difference in Estimated Proportions of Female and Male Civil Servants Answering the Treatment Items Affirmatively across Different Organizational Settings

\subsection{Transformational}

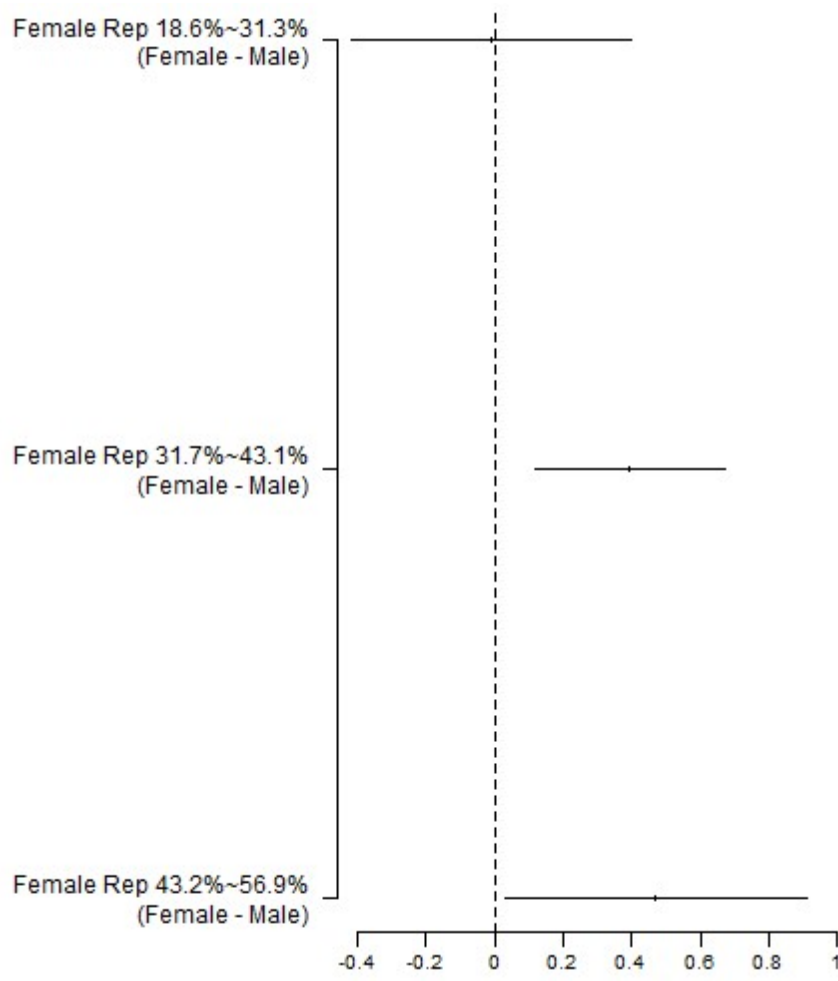

\subsection{Transactional}

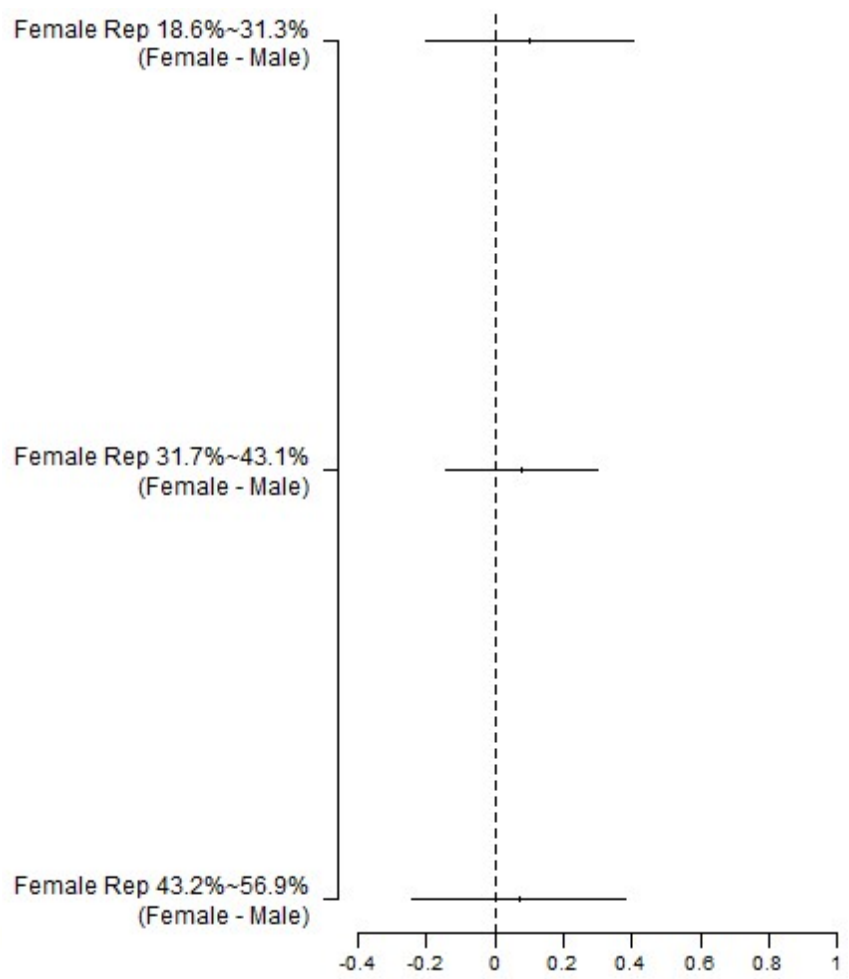

Note: Our sample agencies are divided into three groups according to gender representation in organizations: 1) the lowest $33^{\text {rd }}$ percentile (women's representation between $18.6 \%$ and $31.3 \%$ ), 2) a mid-range (women's representation between $31.7 \%$ and $43.1 \%$ ), and 3 ) the highest $33^{\text {rd }}$ percentile (women's representation between $43.2 \%$ and $56.9 \%$ ). $95 \%$ confidence intervals are shown. 


\section{Appendix}

\section{A. Sampling Design}

Table A1. Size of Samples from 26 Agencies in our Survey

\begin{tabular}{lccc}
\hline Agency & N & $\begin{array}{c}\text { Women's } \\
\text { Representation }\end{array}$ & $\begin{array}{c}\text { Female } \\
\text { Agency Head }\end{array}$ \\
\hline Ministry of Foreign Affairs & 39 & 0.524 & 0 \\
Ministry of Education & 35 & 0.317 & 0 \\
Ministry of Employment and Labor & 29 & 0.456 & 0 \\
Ministry of Land, Infrastructure and Transport & 37 & 0.520 & 0 \\
Ministry of Oceans and Fisheries & 29 & 0.569 & 0 \\
Ministry of Agriculture, Food and Rural Affairs & 30 & 0.215 & 0 \\
Ministry of Health and Welfare & 33 & 0.291 & 0 \\
Ministry of Culture, Sports and Tourism & 35 & 0.549 & 0 \\
Ministry of Environment & 34 & 0.371 & 0 \\
Ministry of Patriots and Veterans Affairs & 30 & 0.431 & 0 \\
Ministry of Trade, Industry and Energy & 37 & 0.291 & 0 \\
Ministry of Economy \& Finance & 33 & 0.323 & 0 \\
Ministry of Government Legislation & 28 & 0.248 & 0 \\
Ministry of Food and Drug Safety & 35 & 0.186 & 1 \\
Korea Customs Service & 28 & 0.365 & 0 \\
Statistics Korea & 32 & 0.274 & 0 \\
Military Manpower Administration & 30 & 0.382 & 0 \\
Korea Forest Service & 26 & 0.269 & 0 \\
Korean Intellectual Property Office & 29 & 0.332 & 0 \\
Public Procurement Service & 35 & 0.441 & 0 \\
Small and Medium Business Administration & 27 & 0.238 & 0 \\
Cultural Heritage Administration & 28 & 0.332 & 1 \\
National Tax Service & 35 & 0.402 & 0 \\
Korea Fair Trade Commission & 25 & 0.248 & 0 \\
Anti-Corruption \& Civil Rights Commission & 29 & 0.186 & 0 \\
Rural Development Administration & 28 & 0.269 & 0 \\
Total & $\mathbf{8 1 6}$ & & 0 \\
\hline
\end{tabular}




\section{B. The Logic of List Experiments}

First, the basic design for list experiments randomizes respondents into control and treatment groups. Then, to those who are selected into the control group, a list of control items is presented. To those who are selected into the treatment group, a list of the same control items plus one more item of interest to the researcher (i.e. the treatment or sensitive item) is presented. Since respondents are assigned to each group through randomization, they have an equal chance of belonging to either the control or the treatment group. This process is illustrated in Figure A1.

\section{Figure A1. Random Assignment and Lists of Items Presented to Control and Treatment Groups}

\section{Control Group}

(1) Item A

(2) Item B

(3) Item $\mathrm{C}$
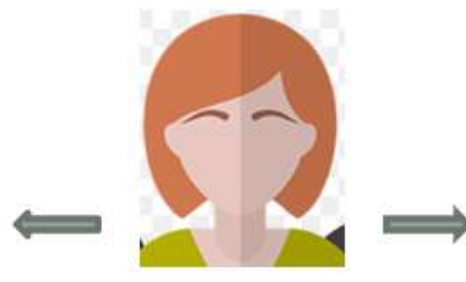

Treatment Group

(1) Item A

(2) Item B

(3) Treatment item

(4) Item C

Note: Items can be shown in a randomized order.

After respondents are randomly assigned to each group and shown a list of items, they are asked to count the number of item(s) on the list applying to them, instead of saying which items apply to them. In this way, respondents may feel it is safe to reveal their truthful answer as well as to answer affirmatively to the sensitive item. More importantly and usefully, this design also helps researchers to estimate the proportion of respondents who are more likely to select the treatment item, given the two main assumptions hold: the no design effect and no liars 
assumptions (Blair \& Imai, 2012). The no design effect assumption means that including a sensitive item does not affect respondents' answers to control items; and the no liars assumption means that respondents do not lie about their answers to a sensitive item (Blair \& Imai, 2012, pp. 51-52). Whether these assumptions hold is important for researchers to be able confidently to estimate the proportion of respondents answering affirmatively to the sensitive item.

As illustrated in Figure A1, suppose that the respondent was randomly assigned to the control group and chose two items in the list. Now suppose that the respondent was randomly assigned to the treatment group (recall that randomization means respondents can be assigned to either group) and chose three items in the list. Based on the two assumptions described above, the respondent's answer was not affected by the design (having one more, sensitive, item in the list), and the respondent was not lying about her answer for a sensitive item. Therefore, in this case, the respondent is likely to choose the sensitive item if the item is presented.

What if the respondent was assigned to the treatment group and chose two items, instead of three, in the list? In this case, given the two assumptions (the no design effect and no liars assumptions) held, she chose the same two control items and did not select the sensitive item. Therefore, the respondent is not likely to choose the sensitive item if the item is presented. Overall, the proportion of respondents answering affirmatively to the sensitive item can be estimated under the two assumptions by simply calculating the difference in the mean response between the treatment and control groups that are randomly selected. 


\section{Mean Responses to Items and Univariate Regression Results}

Table A2 presents mean responses to items for the control and two treatment groups as well as the main univariate results from our list experiment. Entries in the first, second, and fourth columns are mean responses to items. Entries in the third and fifth columns are differences in mean responses to items between treatment and control groups shown in percentage (\%).

Table A2. Mean Response to Control and Treatment Items and its Difference before and after Impeachment

\begin{tabular}{|c|c|c|c|c|}
\hline $\begin{array}{l}\text { Control } \\
\text { Group }\end{array}$ & $\begin{array}{l}\text { Treatment Group } \\
\text { I } \\
\text { (Transformation } \\
\text { al) }\end{array}$ & $\begin{array}{l}\text { Difference (Treat } \\
\text { I-Control) }\end{array}$ & $\begin{array}{l}\text { Treatment Group } \\
\text { II (Transactional) }\end{array}$ & $\begin{array}{l}\text { Difference (Treat } \\
\text { II - Control) }\end{array}$ \\
\hline $\begin{array}{c}2.37 \\
(0.05)\end{array}$ & $\begin{array}{c}2.75 \\
(0.05)\end{array}$ & $\begin{array}{c}38.2^{* * * *} \\
(7.1)\end{array}$ & $\begin{array}{c}2.82 \\
(0.05)\end{array}$ & $\begin{array}{c}45.2^{* * * *} \\
(7.1)\end{array}$ \\
\hline
\end{tabular}

